\title{
Re-Thinking Elective Single Embryo Transfer: Increased Risk of Monochorionic Twinning - A Systematic Review
}

\author{
Margaret Dziadosz ${ }^{\mathrm{a}, \mathrm{b}} \quad$ Mark I. Evans ${ }^{\mathrm{c}, \mathrm{d}}$ \\ aDivision of Maternal Fetal Medicine, Department of Obstetrics \& Gynecology, St. Barnabas Medical Center \\ Livingston, and ${ }^{b} \mathrm{New}$ Jersey Perinatal Associates, Livingston, NJ, ${ }^{\mathrm{C}}$ Mount Sinai School of Medicine, and \\ ${ }^{\mathrm{d} C}$ Comprehensive Genetics, and Fetal Medicine Foundation America, New York, NY, USA
}

\section{Keywords}

Single embryo transfer - Monochorionic twins · Dichorionic twins - In vitro fertilization - Assisted reproductive therapy • Risk

\begin{abstract}
Background/Objectives: Multiple pregnancies have tripled in the United States over the past 3 decades. Attributed to increasing maternal age at delivery but more so assisted reproductive technological advances, an effort has been made to decrease twinning through elective single embryo transfer. We sought to review and evaluate risks of monochorionic twinning as a predictable consequence of increasing utilization of elective single embryo transfer on perinatal outcomes. Primary outcomes included twinning rates, fetal anomalies, growth, preterm birth, and mortality. Secondary outcomes included neurological and pulmonary disability, intrauterine growth restriction, and congenital cardiac anomalies and twin-twin transfusion syndrome. Data sources: PubMed and Embase. Results: A total of 106 studies identified by systematic search met the inclusion criteria. The trend for lower numbers of embryos transferred has inadvertently led to an increase in monochorionic twinning. This is associated with worse outcomes compared to dichorionic twinning and singleton gestations for all outcomes studied. Discussion: Of great concern for monochorionic twins is the
\end{abstract}

\section{KARGER}

(C) 2017 S. Karger AG, Basel

E-Mail karger@karger.com

www.karger.com/fdt risk profile of significant morbidity and mortality. Transfer of 2 embryos should be considered to avoid higher risks inherent to the shared placental phenomena related to monochorionic twins.

(c) 2017 S. Karger AG, Basel

\section{Background}

Over the past 2 decades, infertility treatments, particularly IVF, have dramatically increased the success rate for infertile couples to have their own biological children. One common side effect, however, was a tremendous increase in multiple pregnancies which rose rapidly in the 1990s. For triplets and higher-order multiples, the peak incidence was around 2003. As better methods for control of ovulation medications, improvements in laboratory and clinical methods, and the realization of the increased risks of multiples evolved, the incidence has been steadily falling. Improved control of ovulation methods and extended culturing with blastocyst transfer have allowed for the reduction in the number of embryos transferred while maintaining satisfactory pregnancy success rates. However, blastocyst transfers have much higher rates of monozygotic twinning.

In the 1980s, it was commonly debated whether transfer of 4 or more embryos was appropriate in order to increase successful take home pregnancy rates. The debate

Mark I. Evans, MD

Comprehensive Genetics, PLLC

131 E 65 th Street

New York, NY 10065 (USA)

E-Mail evans@compregen.com 
later fell to 3 embryos for transfer and then 2. Most recently, there is considerable pressure to make elective single embryo transfer (eSET) the standard of care. In jurisdictions where IVF is routinely covered by insurance or government programs, there is the luxury of taking multiple cycles to achieve a pregnancy. However, in locations where out of pocket costs can exceed USD 15,000-20,000 per cycle, there is great pressure to achieve a pregnancy in 1 cycle - thus historically increasing the number of embryos transferred per cycle.

Society for Assisted Reproductive Technology (SART) data show that in women under age 35 at delivery, the percentage of eSET increased from $4.5 \%$ in $2007,9.6 \%$ in 2010 to $22.5 \%$ in 2013 [1]. The average number of embryos transferred has fallen from 2.2 to 2.0 to 1.8 , respectively. As such, twinning from assisted reproductive therapies (ART) has decreased overall. When a single implanted embryo splits, the most common outcome is a monochorionic diamniotic (MCDA) twin pair. This type of twinning occurs in about $3 \%$ of ART cases and may be influenced by zona pellucida manipulation and extended cultures [2,3]. Vital to note and counsel, however, MCDA twins have a vastly increased risk profile compared to dichorionic diamniotic (DCDA) twins. In addition, reducing MCDA twins is generally not done as this has a very high loss rate and residual neurological impairment rates are $6-10 \%$ in the surviving fetus [4]. As such, we present here a contrarian view and suggest that it may be preferable to continue to routinely transfer 2 embryos. This will increase the pregnancy rate but also the rate of DCDA twins and occasionally dichorionic-triamniotic triplets. If this option is chosen over eSET, then testing the health of both fetuses can be entertained. If desired, reduction to a singleton can be employed to further optimize maternal and neonatal outcomes [5].

\section{Objective}

The purpose of this review is to evaluate current risks of monochorionic twinning through a systematic review of the literature and to summarize the available evidence from existing clinical trials. These data may allow for guided management among caretakers to elect for or against eSET.

\section{Data Sources}

This systematic review was performed based on the Preferred Reporting Item for Systematic Review and Meta-analysis (PRISMA-IBD) recommendations [6]. All data were obtained from previously published studies, and therefore Institutional Review Board approval was exempt.

\section{Search Strategy}

A systematic literature search was performed, with studies identified by searching PubMed and Embase (January 2005 to October 2016). To obtain additional, relevant data, we also searched the Cochrane Database of Systematic Reviews, the Cochrane Controlled Trials Registry, and hand-examined reference lists from selected studies. Broad search terms were initially used to ensure that the most extensive range of publications was identified as follows: (maternal OR monozygotic twins) AND (fetal outcomes OR fetus outcomes OR pregnancy outcomes OR neonatal outcomes OR pregnancy complications OR maternal mortality OR maternal outcomes) AND (risks OR rates). After which, search terms were further limited to (maternal twins OR monozygotic twins) AND (fetal outcomes OR fetus outcomes OR neonatal outcomes) AND (risk OR risk factors) AND (IUGR OR preterm OR stillbirth OR anomaly OR anomalies OR mortality OR morbidity) AND (fraternal twins OR dizygotic twins) AND (fetal outcomes OR fetus outcomes OR neonatal outcomes) AND (risk OR risk factors) AND (IUGR OR preterm OR stillbirth OR anomaly OR anomalies OR mortality OR morbidity). Results were limited to English-language, peer-reviewed, and human studies.

\section{Eligibility and Outcome Measures}

Inclusion criteria required study of monochorionic twin gestations and reported outcomes compared to that of singleton gestations or dichorionic twin gestations. Types of comparative data collected included epidemiological data, cost analysis, and fetal and maternal morbidity and mortality data. Our primary outcomes evaluated included twinning rates, fetal anomalies, growth, preterm birth, and mortality. Predefined secondary outcomes included neurological disability, pulmonary disability, intrauterine growth restriction (IUGR), and congenital cardiac anomalies and twin-twin transfusion syndrome (TTTS).

\section{Study Selection}

Manuscript titles and abstracts identified by the literature search were screened. The material and methods of each article that was deemed relevant were reviewed to determine eligibility. The complete manuscript was then reviewed to confirm eligibility.
82

Fetal Diagn Ther 2017;42:81-91

DOI: $10.1159 / 000464286$
Dziadosz/Evans 
Fig. 1. PRISMA flow diagram. This figure illustrates the systematic search of included and excluded articles.

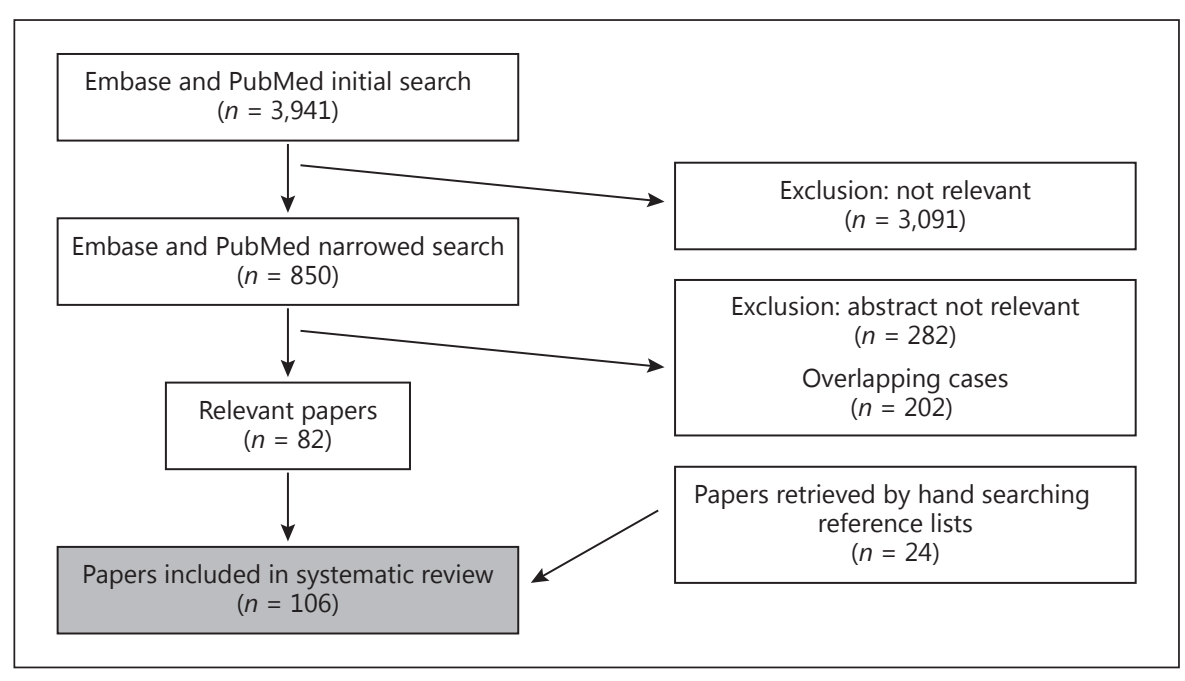

\section{Data Extraction}

For each included article, we extracted the type of gestation and relevant outcome information pertaining to predetermined outcome data. Large studies were interrogated for potential overlap. Our primary goal was to evaluate the most current risks of monochorionic twinning compared to dichorionic twinning and singleton gestations. The Meta-analysis of Observational Studies in Epidemiology guidelines were followed for this systematic review [7].

\section{Results}

The systematic search produced 3,941 results. After more defined, secondary terms were applied, 850 publications remained. Titles and abstracts of these records were screened, resulting in the exclusion of an additional 484 records (282 were not relevant and 202 overlapped between databases). Of 366 relevant articles, 284 were excluded due to insufficient outcome data or non-peer-reviewed sources of origin. An additional 24 articles of importance, published between 1978 and 2004, were retrieved by hand searching reference lists of 82 relevant articles. A total of 106 articles met final inclusion criteria for systematic review (Fig. 1). Twenty-two relevant articles informed epidemiological data, 22 provided data about fetal anomalies, 13 yielded relevant information about fetal growth, 8 about preterm birth, 25 informed specific effects of single placentation, 19 informed neurological disability, 3 informed pulmonary disability, and 20 pertained to neonatal mortality, with some overlap between groups.

Re-Thinking eSET

\section{Epidemiology}

The twinning rate, or births in twin deliveries per 1,000 total births, tripled from 1980 through 2009 to 33.2 per 1,000 births [8-16]. After stabilizing for several years, it again rose by $2 \%$ in 2013 to 33.7 per 1,000 births $[17,18]$. The twinning rate increased most among non-Hispanic blacks and Hispanic women but has remained stable among non-Hispanic whites. The most recent data reveal that 132,324 neonates were born as twins in 2013. Of these, $11.3 \%$ were born at $<32$ completed weeks, and $56 \%$ were born at $<37$ completed weeks [18].

Naturally conceived monozygotic twinning remains constant at 3-5 per 1,000 births; two-thirds of naturally occurring monozygotic twins are MCDA, but they represent only about $20 \%$ of total twins because of the tripling of total twin births from infertility treatments. Rising rates of multifetal gestations are associated with ART and also with increasing maternal age at delivery [19-23]. The multiple birth rate increased to 71 per 1,000 live births for maternal age over 40 at conception compared to 16.3 per 1,000 at age 20 . Elderly gravidas experience more obstetric complications including hypertensive disorders or pregnancy, diabetes, abruption, and labor abnormalities. These maternal morbidities are compounded by maternal complications inherent to a multiple gestation including hyperemesis, diabetes, hypertensive disorders, anemia, hemorrhage, and cesarean delivery [24-26].

Twin gestations are significantly more costly than singleton pregnancies, incurring a 10 times greater cost in the first year of life from prematurity and associated complications $[27,28]$. This is mostly because infants born of twin gestations have a higher frequency of fetal and neonatal morbidity and mortality compared to singletons,

Fetal Diagn Ther 2017;42:81-91 DOI: $10.1159 / 000464286$ 
which is most closely associated with preterm birth. In 2013, according to the National Vital Statistics Report, 1 of every 2 twins were born either preterm or had a low birth weight $(<2,500 \mathrm{~g})$ and $9.75 \%$ were born with a weight of $<1,500 \mathrm{~g}$ [29].

Among twins, MCDA gestations pose greater risk than DCDA pregnancies. They pose a disproportionate disease burden on the fetuses and live-born neonates as a result of a single, shared placenta.

\section{Anomalies}

Overall, multifetal gestations have a greater risk of congenital anomalies than singletons.

\section{Dichorionic}

For Mendelian disorders, there are 2 chances per each pregnancy. So, for 1 of 2 dizygotic twins the risk of at least 1 being affected is: $3 / 4$ that the first one is not affected $x$ $3 / 4$ that the second one is not affected, or $9 / 16$ that neither are affected and thus $7 / 16(44 \%)$ that at least 1 is affected. For chromosomal abnormalities, the maternal age-related risk of having 1 of 2 fetuses affected compared to maternal age-related singleton gestations is almost double. Therefore, a woman carrying dichorionic twins at the age of 30 has the risk portfolio for carrying an aneuploid affected child equal to that of a 35-year-old mother carrying a singleton [30].

\section{Monochorionic}

For Mendelian and chromosomal anomalies, whatever one is, so is the other, so the overall incidence is equal to singletons in MCDA twins. However, although MCDA twins are of presumed identical genetic makeup, they are more likely to be phenotypically discordant for major structural anomalies with the risk of major structural anomalies being $6-8 \%$. This is much higher than for both DCDA twins (1-2\%) or singleton gestations [31, 32].

The risk of structural anomalies alone in MCDZ is slightly higher than twice that of singletons. The etiology of this is more than simply because of the added probabilities of more than 1 fetus to consider. There is a higher prevalence of midline and lateral defects including cloacal extrophy, anal atresia, anencephaly, spine defects, and cardiac defects in MCDA twins. This may be explained by the more difficult segmentation, where major body axes rearrange, in a MCDA gestation, as well as early hypoxia and damage to the early embryo that divides $[33,34]$. In addition, local epigenetic factors may influence gene expression differently between the MCDA pair [35].
Fetal Diagn Ther 2017;42:81-91 DOI: $10.1159 / 000464286$
MCDA gestations face more complications due to the high likelihood of unbalanced volume distribution of placental vascular supply leading to TTTS, twin anemia polycythemia sequence (TAPS), and selective fetal growth restriction. Because of vascular connections in a single placenta causing unbalanced transfusion, an anomaly in a single twin may negatively affect a healthy co-twin. The pathology can be either due to compounding hemodynamic instability or with eventual death of the co-twin that occurs in $10-25 \%$ of cases. Cerebral damage occurs in a quarter of the surviving twins upon death of a co-twin due to exsanguination into the circulation of the demised twin and detrimental deoxygenation of the survival causing permanent damage $[13,36,37]$.

MCDA gestations also appear to be at increased risk of congenital cardiac anomalies. Though the etiology is not completely understood, it is attributed to both teratogenic-hemodynamic instability and morphogenic anomalous embryological development with early division of the fertilized ovum [38-40]. The risk of congenital heart disease (CHD) is increased by approximately $60 \%$ in twins compared to singletons [41-43]. A large survey from northern England between 1998 and 2010 revealed that MCDA twins are at $82 \%$ increased risk for CHD than DCDA twins and a $292 \%$ increased risk compared to singletons with a prevalence rate of 202.8 per 10,000 total births [44]. MCDA gestations are also specifically at increased risk for more severe $\mathrm{CHD}$ such as single ventricle, hypoplastic left heart, and hypoplastic right heart as well as mild CHD such as atrial and ventricular septal defect (most common anomaly), pulmonary valve stenosis, and patent ductus arteriosus that persists beyond 37 weeks of pregnancy $[34,44]$. At least $5 \%$ of MCDA gestations will have at least a single affected fetus detected, while upwards of 9\% will be affected in cases of TTTS, 15-23 fold higher than the general population $[33,41]$. Therefore, every MCDA pair should be evaluated with fetal echocardiography $[15,16]$. Many of the more severe congenital cardiac anomalies have a high likelihood of intrauterine fetal death, which is especially detrimental to the unaffected twin in an MCDA gestation.

Death of a co-twin increases the risk of long-term cognitive and neuromotor disabilities in MCDA, but not DCDA twins. MCDA survivors have a significant rate of neurological morbidity, reported to be as high as $10-30 \%$ $[45,46]$. DCDA twins have lower Mental Processing Composite Scale scores at 5 years of age compared to matched dichorionic twins [47]. Therefore, selective feticide may be more specifically indicated as an intervention for the unaffected twin in such cases [48].
84
Dziadosz/Evans 


\section{Growth}

Growth discordance is defined as a difference of at least $20 \%$ between fetuses. Gestations with discordant growth, but in which both twins still in the normal range are likely not at significantly increased risk of mortality. However, when there is growth discordance and at least 1 fetus is growth restricted, there is nearly an 8-fold increased risk of major neonatal morbidity [49-54]. Growth-restricted twins also have a greater rate of both morbidity and mortality when compared to age-related growth-restricted singletons [55].

Selective IUGR is associated with both fetal mortality and poor neurological outcomes. It occurs due to disproportionate placental sharing due to abnormal vascular connections. It may be diagnosed either of 2 ways: both a fetal weight of less than the 10th percentile with or without significant growth discordance or simply a growth discordance greater than $25 \%$ between twins [8-10, 25, 56].

Monochorionic

Selective IUGR in MCDA twins is associated with increased risk of demise of the smaller twin and neurological damage in the larger twin. The incidence of neurological damage occurring in the larger twin persists even when the smaller co-twin survives [25].

\section{Preterm Birth}

Twin pregnancies are 6 times more likely to deliver preterm and 13 times more likely to delivery prior to 32 weeks' gestation.

\section{Monochorionic}

MCDA gestations have an $87 \%$ likelihood of delivering preterm, which is significantly more common than both DCDA and singleton gestations. They are more significantly likely to deliver prior to 28 weeks, 34 weeks, and more likely to experience NICU admission and intrauterine fetal demise $[57,58]$. Often, this is due to other inherent morbidities experienced by MCDA twins, such as IUGR and preeclampsia [59]. Simoes et al. [60] studied fetal outcomes of twin gestations based on chorionicity only in ART mothers and found that MCDA twins conceived by ART were significantly more likely to be delivered preterm and to have lower birth weights. The higher prematurity rates also led to an increased early neonatal death rate in MCDA twins.

Although it is agreed upon that the optimal timing of delivery is earlier for twins than singletons, controversy remains regarding optimal delivery time balancing the

Re-Thinking eSET risks of prematurity and mortality, with several large studies promoting delivery between $37-38$ weeks' gestation $[61,62]$. In addition to medically indicated or spontaneous labor causing preterm birth in MCDA twins, literature supports iatrogenic preterm delivery of MCDA twins. The American College of Obstetricians and Gynecologists recommends delivery of MCDA gestations between 34 0/7 and 37 6/7 weeks [63]. The benefit of promoting late preterm delivery has been studied and confirmed due to a decreased risk of perinatal and neonatal mortality in such cases, which rises with prolonged gestation [64].

\section{Morbidity}

The Single Placenta

Monochorionic. MCDA gestations develop TTTS in $8-15 \%$ of gestations. In dichorionic-triamniotic triplets, the TTTS rate is over $50 \%$ [65]. TTTS accounts for nearly $50 \%$ of the deaths in MCDA gestations [66, 67]. TTTS complicating MCDA gestations is associated with poorer long-term outcomes including a $22-26 \%$ incidence of neurological impairment. Those who undergo laser coagulation have better outcomes, but still have an incidence of neurological impairment upwards of $17 \%$. Development of CP specifically, occurred in $21 \%$ of those with TTTS and 7\% of those with TTTS who underwent laser treatment $[49,68,69]$. TTTS is associated with these risks independent of death of a co-twin. Treatments including laser ablation can yield significantly morbid outcomes to the pregnancy. No data conclusively demonstrate that any intrauterine therapy including amnioreduction or laser ablation improves neurocognitive or neuromotor outcomes [70]. TTTS also lends consequences to the cardiovascular status of the fetuses with progressive decompensation as disease status progresses. The recipient twin develops cardiomyopathy and abnormal diastolic and systolic function [70-73]. Interestingly, MCDA twins conceived after eSET splitting may experience less TTTS [74]. This suggests a potential different embryological process inherent to ART-conceived monozygotic twinning.

The TAPS is another chronic disease sequence affecting MCDA pairs. It involves unbalanced blood distribution between twins leading to anemia in the donor twin and polycythemia in the recipient twin. This condition occurs in approximately $5 \%$ of MCDA pregnancies spontaneously. It is seen even more frequently (12\%) after fetoscopic laser treatment for TTTS [75-80] Poor neurodevelopmental outcomes including isolated cognitive delay, motor delay and cerebral palsy rates range greatly be-

Fetal Diagn Ther 2017;42:81-91

DOI: $10.1159 / 000464286$ 
tween 2 and $20 \%$ in both the donor and recipient twins who are affected by TAPS [81].

Cognitive development is impaired in twins compared to singletons according to the Baley Scales of Infant Development Index $[82,83]$ in preterm infants. There is consistent cognitive disadvantage among twins seen in population-based studies [84]. Fifteen percent of MCDA pairs affected by TTTS, growth discordance, or death of a co-twin will have an IQ that is $>2$ standard deviations below the mean compared to $3 \%$ of DCDA twins [85]. An exception to this includes a Danish cohort of ninth graders which did not consider children disabled and not available for study in the normal school system $[79,86]$.

Autism spectrum disorders are reported to be 10- to 14fold higher in MCDA twins and 4.5-fold higher in dizygotic twins compared to singletons $[87,88]$. This is likely compounded by lower birth weight in twins, lower gestational age at birth compared to singletons, as well as increased parental age, all of which are associated with not only autism spectrum disorders, but also twin pregnancies.

\section{Neurological}

Neurodevelopmental disability is higher in multiple gestations compared to singletons invariably due to lower birth weights and earlier gestational age at delivery. Singletons tend to have higher IQ by $1.4-5.1$ points in a cohort of full-term, normally grown neonates at birth [84]. Though there is no apparent effect of chorionicity on IQ among twin pairs, a difference in IQ has been found among children born from multifetal gestations compared to singletons $[89,90]$. Twins born $<32$ weeks' are 2 times more likely to develop intraventricular hemorrhage (IVH) and periventricular leukomalacia (PVL) compared to singletons born of the same preterm gestational age [91]. Wadhaman et al. [82, 83, 92] reported a large cohort of infants born $<1,000 \mathrm{~g}$ with a higher rate of $\mathrm{CP}$ in twins $(8.4 \%)$ over singletons $(6.3 \%)$ at $18-22$ months of age. For infants born $<36$ weeks', the relative risk of at least 1 twin developing PVL is $2.181(p<0.001)$ compared to singletons. PVL was diagnosed in the first twin $50 \%$ of the time and in both twins $12 \%$ of the time. Monochorionicity was relevant for $27 \%$ of affected twins, thereby indicating a high incidence in DCDA twin pairs as well [69].

Overall, outcomes in multiples are worse than in singletons even after comparing for these covariates. Multifetal gestations pose an increased risk of developing cerebral palsy. The rate of cerebral palsy is $7 \%$ among twins compared to $1.6 \%$ among singletons $[93,94]$. Though the mechanism is undoubtedly complex, the injury causative of development of cerebral palsy in twin gestations is an- tenatal in over $80 \%$ of cases [95-97]. Surprisingly, there is no significant difference between DCDA twins and singletons when controlling for complications of prematurity [98]. Therefore, the difference between twins and singletons may be largely due to MCDA twins.

Monochorionic. Monochorionic gestations are at greater risk of neurological sequelae due to placental vascular anastomoses which allow for hemodynamic imbalances such as hypovolemic shock or cerebral ischemia from hypoperfusion [98]. In a study that looked at infants born $<32$ weeks', MCDA twins were 6 times more likely to develop cerebral palsy compared to DCDA twins after adjusting for gestational age, gender, cesarean delivery, neonatal bacteremia, and preterm rupture of membranes. This is consistent with the notion that MCDA gestations are at a greater risk due to placental and hemodynamic imbalances compared to DCDA that are more comparable to singleton gestations.

There is a higher rate among MCDA twins compared to DCDA twins [95, 99-101]. The type of cerebral palsy is also different in twins. In comparison to singletons, multiples have higher rates of spastic (91 vs. $87 \%$ ) and bilateral ( 73 vs. $65 \%$ ) cerebral palsy. These types are most likely to be associated with white matter injury, namely PVL and also basal ganglia lesions [93].

Twins at term and of normal weight have higher rates of cerebral palsy than singletons. The overall relative risk for cerebral palsy in twins born $\geq 2,500 \mathrm{~g}$ is 3.3-5.5 compared with singleton [102]. Some data findings are inconsistent. A prospective, non-population-based study showed better long-term outcomes at 2 years than expected. The majority of twins had normal development at 2 years. Cerebral palsy was associated with TTTS, death of a co-twin or cystic PVL development, though there was no significant difference between DCDA and MCDA twins otherwise [98]. Another study by Livinec et al. [103] revealed no difference in cerebral palsy rates between MCDA and DCDA twins when covariates including gestational age at delivery, gender, in utero demise of a cotwin, pregnancy complications and receipt of steroids were controlled for. Inconsistency of data is likely attributable to small study numbers, inappropriate consideration of covariates, and overly early age at evaluation for diagnosis of cerebral palsy in many studies.

\section{Pulmonary}

Fifty-seven percent of MCDA twins experienced respiratory distress after birth [59]. A significantly higher number of twins develop respiratory distress syndrome, bronchopulmonary dysplasia, and pneumothorax [104].
86

Fetal Diagn Ther 2017;42:81-91

DOI: $10.1159 / 000464286$
Dziadosz/Evans 
Three percent of MCDA twins affected by TTTS are at risk of development of persistent pulmonary hypertension, compared to $0 \%$ in those unaffected by TTTS [105].

\section{Mortality}

Twins are more likely to not survive the first year of life compared to singletons [18]. The infant mortality among twins reaches $24 \%$ compared to $5.4 \%$ in singletons [ 31,45 , $66,67,71-73,106,107]$. Multifetal gestations are at an increased rate of fetal and infant mortality. 5\% of twin gestations experience death of at least 1 fetus in the second or third trimester. There is a 5 -fold increased risk of stillbirth among twin gestations. MCDA twins have a higher rate of stillbirth than do DCDA twins [108]. Monoamniotic twins have the highest rate of stillbirth, with rates quoted as high as $80 \%$, primarily due to cord accidents due to entanglement in utero. In the event of a rare condition called twin reversed arterial perfusion, or TRAP, where the pump twin perfuses not only itself, but also a nonliving twin via a high-flow, low-resistance circuit, mortality of the pump twin reaches $50 \%$ due to a high likelihood of cardiac failure and hydrops fetalis. After the death of a single fetus in a twin pregnancy, there is a $3 \%$ risk of demise in the co-twin of a dichorionic gestation and $15 \%$ in a MCDA gestation.

In the event that a co-twin survives in a MCDA pair after a single demise, there is significant risk of neurological sequelae in the surviving twin upwards of $18 \%$ [109-113]. Unfortunately, immediate delivery of the surviving twin does not eradicate this risk [114]. There is also risk of neurological abnormality if this occurs in a DCDA pair, though much lower at approximately $1 \%$. There is a 7 -fold increased risk of neonatal death, primarily due to preterm birth among twins $[94,115,116]$.

\section{Discussion}

The aggressive approach of both ovulation induction methods and IVF embryo transfers has led to an unacceptable incidence of multifetal pregnancies in the past decade. These numbers have been dramatically reduced over the past several years - diminishing one problem but replacing it with another $[117,118]$. There are other important considerations to ART as well. Day 3 embryos, with higher-order numbers of cells compared to fresh or day 2 samples, have a higher success rate in ART. It would seem that healthy day 3 embryos that have not undergone freezing or other manipulations causing trauma may lead to fewer anomalies and lower costs.

Re-Thinking eSET
However, data show that there is no difference in outcome when considering day 3 versus day 5/6 embryo transfers. In fact, frozen-thawed embryo transfers fare better than fresh embryos. In twins, neonatal outcomes including birthweight, small-for-gestational age, and prematurity rates were comparable in the vitrified and the fresh group. Furthermore, the rate of major congenital malformations in live-born neonates is comparable between the vitrified group and the fresh group in twins (2.4 vs. 2.7\%; AOR: 0.51; 95\% CI: 0.05-5.72) [119-122].

Embryo quality may vary considerably between laboratories. ART volume, staffing experience, equipment, air quality and organizational issues are just a few of the factors that influence IVF center quality and success rates [123-125]. Grading systems are applied to assess quality based on cell number, cell regularity, fragmentation, and general appearance; this is subjective and allows for significant variation.

Blastocyst transfers have dramatically increased the implantation rate of embryos such that the eSET numbers have risen dramatically. However, there is inherent teratogenicity with extended culturing which leads to both increased monozygotic twinning and increased anomalies - much of it defects of laterality. With loss rates of $10-20 \%$ and neurological impairment rates of $6-12 \%$, with MCDA twins, fetal reduction is not a realistic possibility in the vast majority of instances. Thus, it is "take it or leave it." Neither is a desirable outcome.

If one has 2 embryos, and the choice is to transfer 2 in 1 cycle, or 1 each in 2 cycles, data have shown that the overall pregnancy rate is actually higher with 2 in 1 cycle [126-128]. There is the potential for DCDA twins and rarely dichorionic-triamniotic triplets. In these circumstances, we have shown that in experienced hands, genetic diagnosis of multiples by chorionic villus sampling (CVS) with fetal reduction produces outcomes comparable to having a singleton in the first place [129-132].

Because a genetic evaluation is done, the residual risks of chromosomal and structural anomalies are actually lower than for the typical singleton pregnancy. With the availability of array comparative genomic hybridization, evaluation on CVS obtained villi prior to reduction if chosen by the patient, an even further detailed evaluation can be done to reduce morbidity and mortality [133]. This has to be compared with the delay in obtaining the final diagnosis, which is a downside for patients considering reduction. With the understanding that reduction may not be an option for many individuals due to personal reasons, our experience shows that CVS and reduction are safe, effective, and significantly improve out-

Fetal Diagn Ther 2017;42:81-91 DOI: $10.1159 / 000464286$ 
comes in appropriate cases $[5,129]$. There is extensive literature, as cited in this review, which supports that conclusion. In fact, pediatric data have suggested that the outcome of delivering babies in pregnancies after fetal reduction may be better than the same number without fetal reduction. This may be due to practitioner selection of healthier gestations by a variety of methods, thereby decreasing the residual risk of neonatal abnormalities. It should be observed that there is bias in personal practitioner experience. Risks of fetal reduction procedures likely vary among providers. Data are limited, though experience from amniocentesis, chorionic villous sampling, periumbilical blood sampling and female pelvic surgeries do indicate that high-procedure volume is related to better patient outcomes [134].
On balance, we believe that patients undergoing ART would be best served if they were presented not only the option of eSET but also of transferring 2 embryos. With development of MCDA twins, it is vital that patients understand the inherent risks of this type of twinning. With the transfer of 2 embryos, the singleton pregnancy rate is higher, and if there are DCDA twins or MCDA triplets, there is the possibility of genetic diagnosis and reduction, which clearly improves outcomes.

\section{Disclosure Statement}

Authors disclose any sponsorship or funding arrangements relating to their review and all authors disclose any possible conflicts of interest.

\section{References}

1 Society for Assisted Reproductive Technology: National Summary Report 2013. Atlanta, US Dept of Health and Human Services, 2016.

2 Knopman JM, Krey LC, Oh C, Lee J, McCaffrey C, Noyes N: What makes them split? Identifying risk factors that lead to monozygotic twins after in vitro fertilization. Fertil Steril 2014;102:82-89.

3 Luke B, Brown MB, Wantman E, Stern JE: Factors associated with monozygosity in assisted reproductive technology pregnancies and the risk of recurrence using linked cycles. Fertil Steril 2014;101:683-689.

4 Gebb J, Dar P, Rosner M, Evans MI: Longterm neurologic outcomes after common fetal interventions. Am J Obstet Gynecol 2015;212: 527.e1-e9.

5 Evans MI, Andriole S, Britt DW: Fetal reduction: 25 years' experience. Fetal Diagn Ther 2014;35:69-82.

6 Stewart LA, Clarke M, Rovers M, Riley RD, Simmonds M, Stewart G, et al: Preferred Reporting Items for Systematic Review and Meta-Analyses of individual participant data: the PRISMA-IPD Statement. JAMA 2015;313: 1657-1665.

7 Stroup DF, Berlin JA, Morton SC, Olkin I, Williamson GD, et al: Meta-analysis of observational studies in epidemiology: a proposal for reporting. Meta-analysis Of Observational Studies in Epidemiology (MOOSE) group. JAMA 2000;283:2008-2012.

8 Valsky DV, Eixarch E, Maria Martinez J, Crispi F, Gratacos E: Selective intrauterine growth restriction in monochorionic twins: pathophysiology, diagnostic approach and management dilemmas. Semin Fetal Neonatal Med 2010;15:342-348.
9 Valsky DV, Eixarch E, Maria Martinez J, Gratacos E: Selective intrauterine growth restriction in monochorionic diamniotic twin pregnancies. Prenat Diag 2010;30:719-726.

10 O'Brien WF, Knuppel RA, Scerbo JC, Rattan PK: Birth weight in twins: an analysis of discordancy and growth retardation. Obstet Gynecol 1986;67:483-486.

11 Cordero L, Franco A, Joy SD: Monochorionic monoamniotic twins: neonatal outcome. J Perinat 2006;26:170-175.

12 Moore ES, Elnaggar AC, Wareham JA, Ramsey CJ, Sumners JE: Neonatal functional lung maturity relative to gestational age at delivery, fetal growth, and pregnancy characteristics in triplet births. J Matern Fetal Neonatal Med 2012;25:78-83.

13 Bajoria R, Wee LY, Anwar S, Ward S: Outcome of twin pregnancies complicated by single intrauterine death in relation to vascular anatomy of the monochorionic placenta. Hum Reprod 1999;14:2124-2130.

14 Argoti PS, Papanna R, Bebbington MW, Kahlek N, Baschat A, Johnson A, et al: Outcome of fetoscopic laser ablation for twin-totwin transfusion syndrome in dichorionictriamniotic triplets compared with monochorionic-diamniotic twins. Ultrasound Obstet Gynecol 2014;44:545-549.

15 AIUM practice guideline for the performance of obstetric ultrasound examinations. J Ultrasound Med 2013;32:1083-1101.

16 AIUM practice guideline for the performance of fetal echocardiography. J Ultrasound Med 2013;32:1067-1082.

17 March of Dimes. Premature Birth Report Card. 2015. http://www.marchofdimes.org/ mission/prematurity-reportcard.aspx.
18 Center for Disease Control. Multiple Births. 2015. http://www.cdc.gov/nchs/data/hestat/ pregnancy/2010_pregnancy_rates.pdf.

19 Reynolds MA, Schieve LA, Jeng G, Peterson HB, Wilcox LS: Risk of multiple birth associated with in vitro fertilization using donor eggs. Am J Epidemiol 2001;154:1043-1050.

20 Reynolds MA, Schieve LA, Martin JA, Jeng G, Macaluso M: Trends in multiple births conceived using assisted reproductive technology, United States, 1997-2000. Pediatrics 2003; 111:1159-1162.

21 Kulkarni AD, Kissin DM, Adashi EY: Fertility treatments and multiple births in the United States. N Engl J Med 2014;370:1070-1071.

22 Schiewe MC, Whitney JB, Anderson RE: Potential risk of monochorionic dizygotic twin blastocyst formation associated with early laser zona dissection of group cultured embryos. Fertil Steril 2015;103:417-421.

23 Simoes T, Quieros A, Marujo AT, Valdoleiros S, Silva P, Blickstein I: Outcome of monochorionic twins conceived by assisted reproduction. Fertil Steril 2015;104:629-632.

24 Luke B, Brown MB: Contemporary risks of maternal morbidity and adverse outcomes with increasing maternal age and plurality. Fertil Steril 2007;88:283-293.

25 Gratacos E, Carreras E, Becker J, Lewi L, Enriquez G, Perapoch J, et al: Prevalence of neurological damage in monochorionic twins with selective intrauterine growth restriction and intermittent absent or reversed end-diastolic umbilical artery flow. Ultrasound $\mathrm{Ob}$ stet Gynecol 2004;24:159-163.

26 Conde-Agudelo A, Belizan JM, Lindmark G: Maternal morbidity and mortality associated with multiple gestations. Obstet Gynecol 2000;95:899-904. 
27 Bromer JG, Ata B, Seli M, Lockwood CJ, Seli E: Preterm deliveries that result from multiple pregnancies associated with assisted reproductive technologies in the USA: a cost analysis. Curr Opin Obstet Gynecol 2011;23:168173.

28 Institute of Medicine Committee on Understanding Premature Birth, Assuring Healthy Outcomes; Behrman RE, Butler AS (eds): Preterm Birth: Causes, Consequences, and Prevention. Washington, National Academies Press, 2007.

29 Center for Disease Control: VitalStats. http:// www.cdc.gov/nchs/vitalstats.htm. 2015.

30 Rodis JF, Egan JF, Craffey A, Ciarleglio L, Greenstein RM, Scorza WE: Calculated risk of chromosomal abnormalities in twin gestations. Obstet Gynecol 1990;76:1037-1041.

31 Lewi L, Jani J, Blickstein I, Huber A, Gucciardo L, Van Mieghem T, et al: The outcome of monochorionic diamniotic twin gestations in the era of invasive fetal therapy: a prospective cohort study. Am J Obstet Gynecol 2008;199: 514.e1-8.

32 Lewi L, Van Schoubroeck D, Gratacos E, Witters I, Timmerman D, Deprest J: Monochorionic diamniotic twins: complications and management options. Curr Opin Obstet Gynecol 2003;15:177-194.

33 Springer S, Mlczoch E, Krampl-Bettelheim E, Mailath-Pokorny M, Ulm B, Worda C, et al: Congenital heart disease in monochorionic twins with and without twin-to-twin transfusion syndrome. Prenat Diagn 2014;34:994999.

34 AlRais F, Feldstein VA, Srivastava D, Gosnell K, Moon-Grady AJ: Monochorionic twins discordant for congenital heart disease: a referral center's experience and possible pathophysiologic mechanisms. Prenat Diagn 2011; 31:978-984.

35 Pelech AN, Broeckel U: Toward the etiologies of congenital heart diseases. Clin Perinatol 2005;32:825-844, vii.

36 Bajoria R, Ward SB, Adegbite AL: Comparative study of perinatal outcome of dichorionic and trichorionic iatrogenic triplets. Am J Obstet Gynecol 2006;194:415-424.

37 Evans MI, Lau TK: Making decisions when no good choices exist: delivery of the survivor after intrauterine death of the co-twin in monochorionic twin pregnancies. Fetal Diagn Ther 2010;28:191-195.

38 Manning N, Archer N: A study to determine the incidence of structural congenital heart disease in monochorionic twins. Prenat Diagn 2006;26:1062-1064.

39 Jones KL, Weiss LA, Hagey LR, Gonzalez V, Benirschke K, Chambers CD: Altered lipid metabolism in gastroschisis: a novel hypothesis. Am J Med Genet A 2013;161a:18601865.

40 Mittwoch U: Different gene expressions on the left and the right: a genotype/phenotype mismatch in need of attention. Ann Hum Genet 2008;72:2-9.
41 Bahtiyar MO, Dulay AT, Weeks BP, Friedman AH, Copel JA: Prevalence of congenital heart defects in monochorionic/diamniotic twin gestations: a systematic literature review. J Ultrasound Med 2007;26:1491-1498.

42 Glinianaia SV, Rankin J, Wright C: Congenital anomalies in twins: a register-based study. Hum Reprod 2008;23:1306-1311.

43 Herskind AM, Almind Pedersen D, Christensen K: Increased prevalence of congenital heart defects in monozygotic and dizygotic twins. Circulation 2013;128:1182-1188.

44 Best KE, Rankin J: Increased risk of congenital heart disease in twins in the North of England between 1998 and 2010. Heart 2015;101: 1807-1812.

45 van Heteren CF, Nijhuis JG, Semmekrot BA, Mulders LG, van den Berg PP: Risk for surviving twin after fetal death of co-twin in twintwin transfusion syndrome. Obstet Gynecol 1998;92:215-219.

46 Forrester KR, Keegan KM, Schmidt JW: Neurological impairment in a surviving twin following intrauterine fetal demise of the cotwin: a case study. J Neonatal Perinatal Med 2013;6:83-88.

47 Bodeau-Livinec F, Zeitlin J, Blondel B, Arnaud C, Fresson J, Burguet A, et al: Do very preterm twins and singletons differ in their neurodevelopment at 5 years of age? Arch Dis Child Fetal Neonatal Ed 2013;98:F480-F487.

48 Malhotra A, Menahem S, Shekleton P, Gillam L: Medical and ethical considerations in twin pregnancies discordant for serious cardiac disease. J Perinatol 2009;29:662-667.

49 Lopriore E, Slaghekke F, Vandenbussche FP, Middeldorp JM, Walther FJ, Oepkes D: Cerebral injury in monochorionic twins with selective intrauterine growth restriction and/or birthweight discordance. Am J Obstet Gynecol 2008; 199:628.e1-5.

50 Lopriore E, Sluimers C, Pasman SA, Middeldorp JM, Oepkes D, Walther FJ: Neonatal morbidity in growth-discordant monochorionic twins: comparison between the larger and the smaller twin. Twin Res Hum Genet 2012;15:541-546.

51 Appleton C, Pinto L, Centeno M, Clode N, Cardoso C, Graca LM: Near term twin pregnancy: clinical relevance of weight discordance at birth. J Perinatol Med 2007;35:6266.

52 Cohen SB, Elizur SE, Goldenberg M, Beiner M, Novikov I, Mashiach S, et al: Outcome of twin pregnancies with extreme weight discordancy. Am J Perinatol 2001;18:427-432.

53 Kilic M, Aygun C, Kaynar-Tuncel E, Kucukoduk S: Does birth weight discordance in preterm twins affect neonatal outcome? J Perinatol 2006;26:268-272.

54 Yinon Y, Mazkereth R, Rosentzweig N, JarusHakak A, Schiff E, Simchen MJ: Growth restriction as a determinant of outcome in preterm discordant twins. Obstet Gynecol 2005; 105:80-84.
55 Odibo AO, McDonald RE, Stamilio DM, Ural $\mathrm{SH}$, Macones GA: Perinatal outcomes in growth-restricted twins compared with agematched growth-restricted singletons. Am J Perinatol 2005;22:269-273.

56 Hubinont C, Lewi L, Bernard P, Marbaix E, Debieve F, Jauniaux E: Anomalies of the placenta and umbilical cord in twin gestations. Am J Obstet Gynecol 2015;213(suppl 4):S91S102.

57 Carter EB, Bishop KC, Goetzinger KR, Tuuli MG, Cahill AG: The impact of chorionicity on maternal pregnancy outcomes. Am J Obstet Gynecol 2015;213:390.e1-e7.

58 Ghalili A, McLennan A, Pedersen L, Kesby G, Hyett J: Outcomes of monochorionic diamniotic twin pregnancies: a comparison of assisted and spontaneous conceptions. Aust N Z J Obstet Gynecol 2013;53:437-442.

59 Al Riyami N, Al-Rusheidi A, Al-Khabori M: Perinatal outcome of monochorionic in comparison to dichorionictwin pregnancies. Oman Med J 2013;28:173-177.

60 Simoes T, Queiros A, Marujo AT, Valdoleiros S, Silva P, Blickstein I: Outcome of monochorionic twins conceived by assisted reproduction. Fertil Steril 2015;104:629-632.

61 Kahn B, Lumey LH, Zybert PA, Lorenz JM, Cleary-Goldman J, D’Alton ME, et al: Prospective risk of fetal death in singleton, twin, and triplet gestations: implications for practice. Obstet Gynecol 2003;102:685-692.

62 Cheung YB, Yip P, Karlberg J: Mortality of twins and singletons by gestational age: a varying-coefficient approach. Am J Epidemiol 2000;152:1107-1116.

63 ACOG Committee Opinion No 560: Medically indicated late-preterm and early-term deliveries. Obstet Gynecol 2013;121:908-910.

64 Lee HJ, Kim SH, Chang KH, Sung JH, Choi SJ: Gestational age at delivery and neonatal outcome in uncomplicated twin pregnancies: what is the optimal gestational age for delivery according to chorionicity? Obstet Gynecol Sci 2016;59:9-16.

65 Peeters SH, Middeldorp JM, Lopriore E, Klumper FJ, Oepkes D: Monochorionic triplets complicated by fetofetal transfusion syndrome: a case series and review of the literature. Fetal Diagn Ther 2012;32:239-245.

66 Mosquera C, Miller RS, Simpson LL: Twintwin transfusion syndrome. Semin Perinatol 2012;36:182-189.

67 Berghella V, Kaufmann M: Natural history of twin-twin transfusion syndrome. J Reprod Med 2001;46:480-484.

68 Hikino S, Ohga S, Kanda T, Nakashima T, Yamamoto J, Nakayama $\mathrm{H}$, et al: Long-term outcome of infants with twin-to-twin transfusion syndrome. Fetal Diagn Ther 2007;22:68-74.

69 Resch B, Resch E, Freidl T, Maurer U, Haas J, Muller W: Preterm twin and triplet pregnancies are at increased risk for the development of cystic periventricular leukomalacia. Eur J Paediatr Neurol 2013;17:148-152. 
70 Bahtiyar MO, Emery SP, Dashe JS, WilkinsHaug LE, Johnson A, Paek BW, et al: The North American Fetal Therapy Network consensus statement: prenatal surveillance of uncomplicated monochorionic gestations. Obstet Gynecol 2015;125:118-123.

71 Raboisson MJ, Fouron JC, Lamoureux J, Leduc L, Grignon A, Proulx F, et al: Early intertwin differences in myocardial performance during the twin-to-twin transfusion syndrome. Circulation 2004; 110:3043-3048.

72 Michelfelder E, Gottliebson W, Border W, Kinsel M, Polzin W, Livingston J, et al: Early manifestations and spectrum of recipient twin cardiomyopathy in twin-twin transfusion syndrome: relation to Quintero stage. Ultrasound Obstet Gynecol 2007;30:965-971.

73 Moon-Grady AJ, Rand L, Gallardo S, Gosnell $\mathrm{K}$, Lee H, Feldstein VA: Diastolic cardiac pathology and clinical twin-twin transfusion syndrome in monochorionic/diamniotic twins. Am J Obstet Gynecol 2011;205:279.e1e11.

74 Ben-Ami I, Molina FS, Battino S, et al: Monochorionic diamniotic in vitro fertilization twins have a decreased incidence of twin-totwin transfusion syndrome. Fertil Steril 2016; 105:729-733.

75 Lopriore E, Middeldorp JM, Oepkes D, Kanhai HH, Walther FJ, Vandenbussche FP: Twin anemia-polycythemia sequence in two monochorionic twin pairs without oligopolyhydramnios sequence. Placenta 2007;28: 47-51.

76 Lopriore E, Middeldorp JM, Oepkes D, Klumper FJ, Walther FJ, Vandenbussche FP: Residual anastomoses after fetoscopic laser surgery in twin-to-twin transfusion syndrome: frequency, associated risks and outcome. Placenta 2007;28:204-208.

77 Lewi L, Jani J, Blickstein I, Huber A, Gucciardo L, Van Mieghem T, et al: The outcome of monochorionic diamniotic twin gestations in the era of invasive fetal therapy: a prospective cohort study. Am J Obstet Gynecol 2008;199: 514.e1-e8.

78 Slaghekke F, Kist WJ, Oepkes D, Pasman SA, Middeldorp JM, Klumper FJ, et al: Twin anemia-polycythemia sequence: diagnostic criteria, classification, perinatal management and outcome. Fetal Diagn Ther 2010;27:181-190.

79 Slaghekke F, van Klink JM, Koopman HM, Middeldorp JM, Oepkes D, Lopriore E: Neurodevelopmental outcome in twin anemiapolycythemia sequence after laser surgery for twin-twin transfusion syndrome. Ultrasound Obstet Gynecol 2014;44:316-321.

80 Yarci E, Alyamac Dizdar E, Oncel MY, Kose Cetinkaya A, Derme T, Canpolat FE, et al: Successful management of twin anemia/polycythemia sequence by syngeneic partial exchange transfusion. Fetal Diagn Ther 2014; 36:251-254.
81 van Klink JM, Koopman HM, van Zwet EW, Middeldorp JM, Walther FJ, Oepkes D, et al: Improvement in neurodevelopmental outcome in survivors of twin-twin transfusion syndrome treated with laser surgery. Am J Obstet Gynecol 2014;210:540.e1-e7.

82 Wadhawan R, Oh W, Perritt RL, McDonald SA, Das A, Poole WK, et al: Twin gestation and neurodevelopmental outcome in extremely low birth weight infants. Pediatrics 2009;123:e220-e227.

83 Wadhawan R, Oh W, Vohr BR, Wrage L, Das A, Bell EF, et al: Neurodevelopmental outcomes of triplets or higher-order extremely low birth weight infants. Pediatrics 2011; 127:e654-e660.

84 Ronalds GA, De Stavola BL, Leon DA: The cognitive cost of being a twin: evidence from comparisons within families in the Aberdeen children of the 1950s cohort study. BMJ 2005; 331:1306.

85 Adegbite AL, Castille S, Ward S, Bajoria R: Neuromorbidity in preterm twins in relation to chorionicity and discordant birth weight. Am J Obstet Gynecol 2004;190:156-163.

86 Christensen K, Petersen I, Skytthe A, Herskind AM, McGue M, Bingley P: Comparison of academic performance of twins and singletons in adolescence: follow-up study. BMJ 2006;333:1095.

87 Greenberg DA, Hodge SE, Sowinski J, Nicoll D: Excess of twins among affected sibling pairs with autism: implications for the etiology of autism. Am J Hum Genet 2001;69: 1062-1067.

88 Betancur C, Leboyer M, Gillberg C: Increased rate of twins among affected sibling pairs with autism. Am J Hum Genet 2002;70:1381-1383.

89 Melnick M, Myrianthopoulos NC: The effects of chorion type on normal and abnormal developmental variation in monozygous twins. Am J Med Genet 1979;4:147-156.

90 Melnick M, Myrianthopoulos NC, Christian JC: The effects of chorion type on variation in IQ in the NCPP twin population. Am J Hum Genet 1978;30:425-433.

91 Rettwitz-Volk W, Tran TM, Veldman A: Cerebral morbidity in preterm twins. J Maternal Fetal Neonatal Med 2003;13:218-223.

92 Burguet A, Monnet E, Pauchard JY, Roth P, Fromentin C, Dalphin ML, et al: Some risk factors for cerebral palsy in very premature infants: importance of premature rupture of membranes and monochorionic twin placentation. Biol Neonat 1999;75:177-186.

93 Petterson B, Nelson KB, Watson L, Stanley F: Twins, triplets, and cerebral palsy in births in Western Australia in the 1980s. BMJ 1993; 307:1239-1243.

94 Scher AI, Petterson B, Blair E, Ellenberg JH, Grether JK, Haan E, et al: The risk of mortality or cerebral palsy in twins: a collaborative population-based study. Pediatr Res 2002;52: 671-681.

95 Pharoah P: Neurological outcome in twins. Semin Neonatol 2002;7:223-230.
96 Pharoah PO: Risk of cerebral palsy in multiple pregnancies. Clin Perinatol 2006;33: 301-313.

97 Pharoah PO, Dundar Y: Monozygotic twinning, cerebral palsy and congenital anomalies. Hum Reprod Update 2009;15:639-648.

98 Hack KE, Koopman-Esseboom C, Derks JB, Elias SG, de Kleine MJ, Baerts W, et al: Long-term neurodevelopmental outcome of monochorionic and matched dichorionic twins. PLoS One 2009;4:e6815.

99 Pharoah PO, Price TS, Plomin R: Cerebral palsy in twins: a national study. Arch Dis Child Fetal Neonatal Ed 2002;87:F122F124.

100 Topp M, Huusom LD, Langhoff-Roos J, Delhumeau C, Hutton JL, Dolk H: Multiple birth and cerebral palsy in Europe: a multicenter study. Acta Obstet Gynecol Scand 2004;83:548-553.

101 Bonellie SR, Currie D, Chalmers J: Comparison of risk factors for cerebral palsy in twins and singletons. Dev Med Child Neurol 2005;47:587-591.

102 Lorenz JM: Neurodevelopmental outcomes of twins. Semin Perinat 2012;36:201-212.

103 Livinec F, Ancel PY, Marret S, Arnaud C, Fresson J, Pierrat V, et al: Prenatal risk factors for cerebral palsy in very preterm singletons and twins. Obstet Gynecol 2005;105: 1341-1347.

104 Fumagalli M, Schiavolin P, Bassi L, Groppo M, Uccella S, De Carli A, et al: The impact of twin birth on early neonatal outcomes. Am J Perinatol 2016;33:63-70.

105 Delsing B, Lopriore E, Blom N, Te Pas AB, Vandenbussche FP, Walther FJ: Risk of persistent pulmonary hypertension of the neonate in twin-to-twin transfusion syndrome. Neonatology 2007;92:134-138.

106 Lopriore E, Stroeken H, Sueters M, Meerman R-J, Walther F, Vandenbussche F: Term perinatal mortality and morbidity in monochorionic and dichorionic twin pregnancies: a retrospective study. Acta Obstet Gynecol Scand 2008;87:541-545.

107 Luke B, Brown MB: The changing risk of infant mortality by gestation, plurality, and race: 1989-1991 versus 1999-2001. Pediatrics 2006;118:2488-2497.

108 Simoes T, Queiros A, Marujo AT, Valdoleiros S, Silva P, Blickstein I: Prospective risk of intrauterine death of monochorionic twins: update. J Perinat Med 2016;44:871874.

109 Lee YM, Wylie BJ, Simpson LL, D'Alton ME: Twin chorionicity and the risk of stillbirth. Obstet Gynecol 2008;111:301-308.

110 Morikawa M, Yamada T, Yamada T, Sato S, Cho K, Minakami H: Prospective risk of stillbirth: monochorionic diamniotic twins vs. dichorionic twins. J Perinat Med 2012; $40: 245-249$. 
111 Morikawa M, Yamada T, Yamada T, Sato S, Minakami H: Prospective risk of intrauterine fetal death in monoamniotic twin pregnancies. Twin Res Hum Genet 2012;15: 522-526.

112 Danon D, Sekar R, Hack KE, Fisk NM: Increased stillbirth in uncomplicated monochorionic twin pregnancies: a systematic review and meta-analysis. Obstet Gynecol 2013;121:1318-1326.

113 Hillman SC, Morris RK, Kilby MD: Co-twin prognosis after single fetal death: a systematic review and meta-analysis. Obstet Gynecol 2011;118:928-940.

114 Karageyim Karsidag AY, Kars B, Dansuk R, Api O, Unal O, Turan MC, et al: Brain damage to the survivor within $30 \mathrm{~min}$ of co-twin demise in monochorionic twins. Fetal Diagn Ther 2005;20:91-95.

115 Glinianaia SV, Obeysekera MA, Sturgiss S, Bell R: Stillbirth and neonatal mortality in monochorionic and dichorionic twins: a population-based study. Hum Reprod 2011; 26:2549-2557.

116 Ong SS, Zamora J, Khan KS, Kilby MD: Prognosis for the co-twin following singletwin death: a systematic review. BJOG 2006; 113:992-998.

117 Martin JA, Hamilton BE, Osterman MJ: Three decades of twin births in the United States, 1980-2009. NCHS Data Brief 2012; $80: 1-8$.

118 Committee on Practice Bulletins-Obstetrics; Society for Maternal-Fetal Medicine: Practice Bulletin No. 169. Multifetal Gestations: Twin, Triplet, and Higher-Order Multifetal Pregnancies. Obstet Gynecol 2016;128:e131-e146.
119 Roque M, Lattes K, Serra S, Sola I, Psych B, Geber S, Carreras R, Checa MA: Fresh embryo transfer versus frozen embryo transfer in in vitro fertilization cycles: a systematic review and meta-analysis. Fertil Steril 2014; 99:156-162.

120 Roque M, Valle M, Guimaraes F, Sampaio M, Geber S: Freeze-all policy: fresh versus froze-thawed embryo transfer. Fertil Steril 2015;103:1190-1193.

121 Maxwell SM, Melzer-Ross K, McCulloh DH, Grifo JA: A comparison of pregnancy outcomes between day 3 and day 5/6 embryo transfers: does day of embryo transfer really make a difference? J Assist Reprod Genet 2015;32:249.

122 Belva F, Bonduelle M, Roelants M, Verheyen G, Van Landuyt L: Neonatal health including congenital malformation risk of 1,072 children born after vitrified embryo transfer. Hum Reprod 2016;31:1610-1620.

123 Mortimer ST, Mortimer D: Quality and Risk Management in the IVF Laboratory, ed 2. Cambridge, Cambridge University Press, 2015, pp 39-48.

124 Heitmann RJ, Hill MJ, James AN, Schimmel T, Segars JK, Csokmay JM, Cohen J, Payson MD: Live births achieved via IVF are increased by improvements in air quality and laboratory environment. Reprod Biomed 2015;31:364-371.

125 Palter S, DiPaola K, Sparks AE, Degelos S, Koulianos GT, Young J, Halicigil C, Yalcinkaya T, She E, Bartolucci A: Multi-center study: innovative control of ambient air quality in multiple IVF laboratories is associated with statistically significant improvements in clinical outcomes - analysis of 5319 cycles. Fertil Steril 2016;106:e27.
126 Lawlor DA, Nelson SM: Effect of age on decisions about the numbers of embryos to transfer in assisted conception: a prospective study. Lancet 2012;379:521-527.

127 Nelson SM, Lawlor DA: Predicting live birth outcomes after in vitro fertilisation. BJOG 2012;119:1668; author reply 1669 .

128 Smith AD, Tilling K, Nelson SM, Lawlor DA: Live-birth rate associated with repeat in vitro fertilization treatment cycles. JAMA 2015;314:2654-2662.

129 Evans MI, Kaufman MI, Urban AJ, Britt DW, Fletcher JC: Fetal reduction from twins to a singleton: a reasonable consideration? Obstet Gynecol 2004;104:102-109.

130 Evans MI, Rosner M, Andriole S, Alkalay A, Gebb J, Britt DW: Evolution of gender options in multiple pregnancy management. Prenat Diagn 2013;33:935-939.

131 Rosner M, Pergament E, Andriole S, Gebb J, Dar P, Evans MI: Detection of genetic abnormalities using CVS and FISH prior to fetal reduction in sonographically normal appearing fetuses. Prenat Diagn 2013;33:940944.

132 Dodd JM, Crowther CA: Reduction of the number of fetuses for women with a multiple pregnancy. Cochrane Database Syst Rev 2012;10:CD003932.

133 Evans MI, Wapner RJ, Berkowitz RL: Noninvasive prenatal screening or advanced diagnostic testing: caveat emptor. Am J Obstet Gynecol 2016;215:298-305.

134 Walter A: Every woman deserves a highvolume gynecologic surgeon. Am J Obstet Gynecol 2016;216:139. 